\title{
Multifocal Malignant Lymphoma of the Breast
}

\author{
Elmas Ozgun ${ }^{1}$, Deniz Tuncel ${ }^{1}$, Ayca Tan ${ }^{2}$, Aynur Albayrak ${ }^{3}$, Sehnaz Sayhan ${ }^{4}$, Nurten Bozlak ${ }^{1}$ \\ ${ }^{1}$ Department of Pathology, I. Sevki Atasagun State Hospital, Nevsehir, Turkey; ${ }^{2}$ Department of Pathology, Denizli State Hospital, \\ Denizli, Turkey; ${ }^{3}$ Department of Pathology, Ankara Dıskapi Yildirim Beyazit Training and Research Hospital, Ankara, Turkey; \\ ${ }^{4}$ Department of Pathology, Denizli Servergazi State Hospital, Denizli, Turkey. \\ Email: draycatan@gmail.com
}

Received April $4^{\text {th }}, 2013$; revised May $14^{\text {th }}, 2013$; accepted June $20^{\text {th }}, 2013$

Copyright (C) 2013 Elmas Ozgun et al. This is an open access article distributed under the Creative Commons Attribution License, which permits unrestricted use, distribution, and reproduction in any medium, provided the original work is properly cited.

\begin{abstract}
Primary non-Hodgkin's lymphomas is an uncommon disease representing approximately $0.13 \%$ of all reported malignant mammary neoplasms. Clinically they are mainly observed as solitary lesions, but may also be seen as multiple foci. Herein, we present a very rare case with the diagnosis of multifocal malignant lymphoma of the breast. Case: A 56year-old-female patient with a right palpable breast mass admitted to the hospital. Mammography and ultrasonography findings showed two different foci of hypoechoic solid mass forming lesion in the right breast. Excisional biopsy has been performed. In the histopathological evaluation, both lesions demonstrated foci of necrosis; mitotically active tumor cells with large nucleus and prominent nucleoli. The immunohistochemical analysis revealed diffuse LCA, CD20, CD43, focal CD68 positivity while pancytokeratin, EMA, CD34, SMA were negative. The case was diagnosed as Diffuse Large B-cell Lymphoma. We report a very rare case with a diagnosis of multifocal primary non-Hodgkin's lymphoma of the breast.
\end{abstract}

Keywords: Lymphoma; Breast; Multifocal

\section{Introduction}

Primary non-Hodgkin's lymphoma is an exceedingly rare entity [1]. The disease usually manifests as a painless mass recognized incidentally. Most of the cases are solitary [2]. Multifocal and diffuse infiltrating cases have also been reported [3]. The current case describes a very rare entity with the diagnosis of multifocal malignant lymphoma of the breast with a detailed clinicopathologic evaluation.

\section{Case Report}

A 56-year-old female was admitted to the general surgery clinics of our hospital due to a palpable mass on the right breast. After the physical examination, an ultrasonography of the right breast revealed two hypoechoic, heterogenous solid mass with the sizes of $65 \times 42 \mathrm{~mm}$ and $45 \times 25 \mathrm{~mm}$. An excisional biopsy was performed. On the macroscopical evaluation, a solid tan tumor with brownish foci has been observed.

On the microscopical examination; the tumor was condensely infiltrating the breast parenchyma with wide necrosis areas (Figure 1). Neoplastic cells were consist of atypical large, irregular, mitotically active lymphoid cells with hyperchromatic nucleus, prominent nucleoli and occasional clear cytoplasm (Figure 2). The ducts and acini were surrounded by the tumor cells (Figure 3 ).

On the immunohistochemical evaluation; LCA, CD20, CD43 showed diffusely and strong positivity while CD68 showed focal weak positivity with the absence of staining for pancytokeratin and EMA (Figures 4-7). CD34 was immunoreactive in the vascular endothelial cells. SMA was immunoreactive in ductal myoepithelial cells. The results confirmed the diagnosis of diffuse large B cell lymphoma.

According to the histopathological diagnosis, chemotherapy has been applied for the treatment.

\section{Discussion}

Non-Hodgkin Lymphomas of the breast is a very rare entity [4]. The prevalance of the disease accounts $1.7 \%$ among the extranodal non-Hodgkin lymphomas [5] and $0.13 \%$ among all the reported malignant mammary neoplasms [6-8]. The neoplasm appears either as a primary extranodal disease or secondary targets of a systemic disease. Primary lymphomas are limited to the breast. Secondary lesions take place in the breast as a result of 


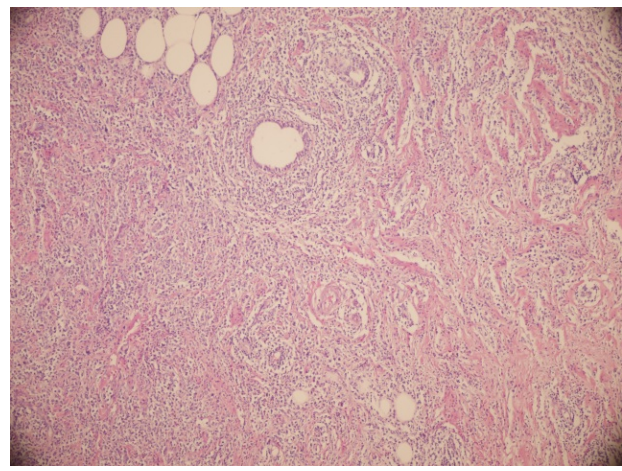

Figure 1. Infiltration of tumor cells around the normal mammarial duct, $H \& E$ stain, $\times 100$.

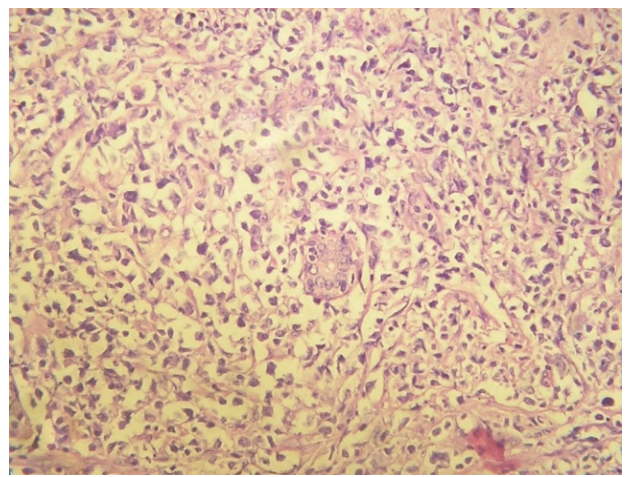

Figure 2. Infiltration of tumor cells around the normal mammarial duct, $H \& E$ stain, $\times 200$.

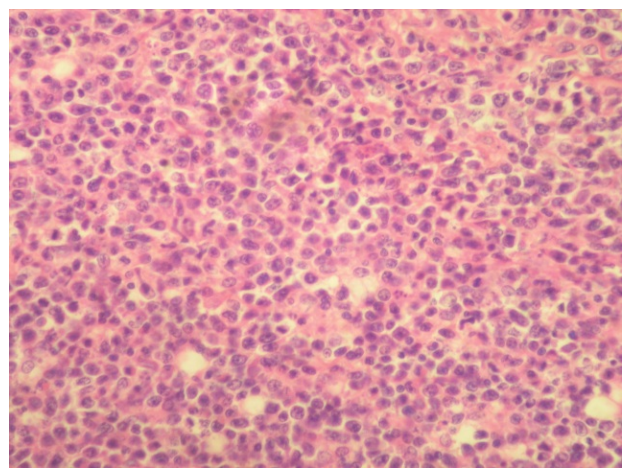

Figure 3. Diffuse atypical lymphoid cells, H\&E stain, $\times 400$.

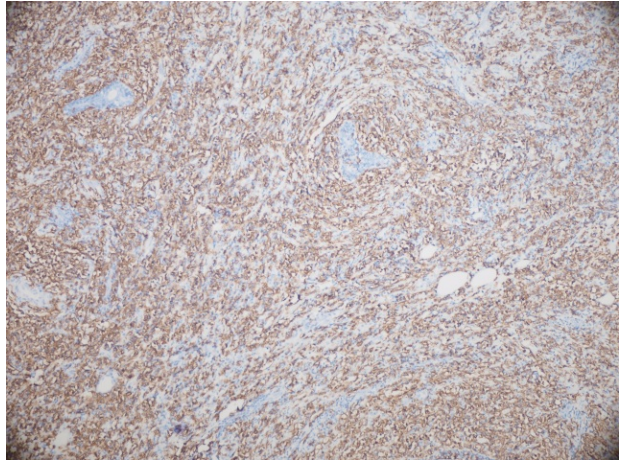

Figure 4. LCA immunoreactivity in tumor cells, $\times 100$.

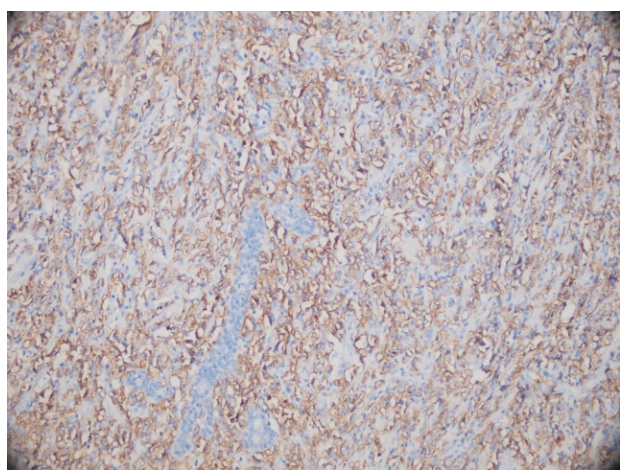

Figure 5. CD 20 immunoreactivity in tumor cells, $\times 200$.

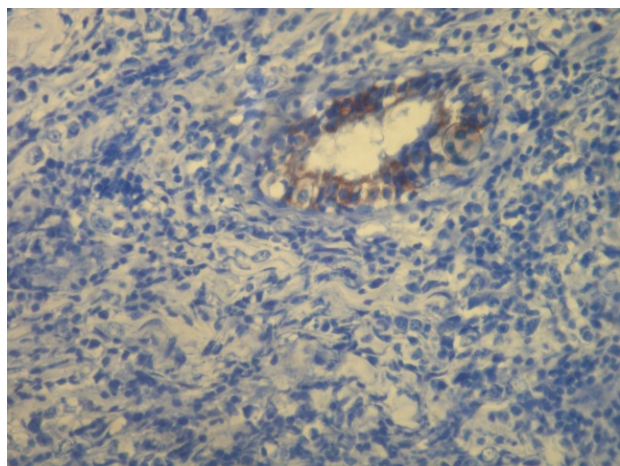

Figure 6. EMA immunoreactivity in normal mammarial duct, $\times \mathbf{4 0 0}$.

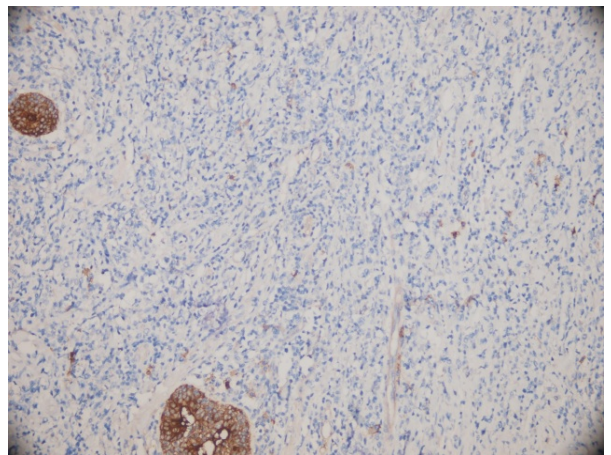

Figure 7. Pancytokeratin immunoreactivity in normal mammarial duct, $\times \mathbf{2 0 0}$.

disseminated neoplasms. Recurrences are also observed in the breast [5].

To be declared as primary breast lymphoma, majority of the reports follow the criteria described by Wiseman and Liao: 1) there is an adequate pathologic specimen demonstrating close association of the lymphomatous infiltrate and breast tissue; 2) there is no evidence of concurrent widespread disease or preceding extramammary lymphoma; 3) the breast is the clinical site of presentation, but ipsilateral lymph node involvement is considered acceptable if both lesions develop simultaneously [9]. $20 \%$ of the reported primary lesions are bilateral [6]. Likewise in the current case, as a very rare entity multi- 
focal lymphoma on the breast have also been seldomly reported in the literature [10].

The disease mainly occurs in the fifth decade and is more common on the right breast $[11,12]$. The majority of the cases reported are female while there are very rare cases seen in males described in the literature [13,14].

Breast lymphoma and carcinoma have a similar clinical and radiological appearance. Patients contact with the physicians for a painless enlarging mass [15]. In our case, the patient admitted to the hospital with a right palpable breast mass. Ultrasonography usually shows an irregular, homogenous mass with high distal acoustic image. Mammography can reveal solitary or multiple, regular masses which can be in different sizes without calcification [2]. In our case, ultrasonography of the right breast revealed two hypoechoic, heterogenous solid mass in concordance with the literature. The main diagnostic essential is the histopathologic evaluation.

Macroscopically, the neoplasm varies between 1 to 12 $\mathrm{cm}$ in diameter. It appears with mostly well-defined borders with a solid, gray-white cut-surface. Areas of necrosis demonstrates as soft, brownish spots.

Microscopically, lymphomas of the breast consist of atypical lymphoid cell populations diffusely infiltrating the parenchyma of the breast. In the center of the lesion, partially or totally obliterated ducts and acini may be observed. Intense sclerotic reaction in the stroma can be impressive in some cases [10]. It is essential to confirm the $\mathrm{B}$ cell nature with the spesific B cell immunohistochemical markers.

In the differential diagnosis; reactive lymphoid infiltration, medullary carcinoma, amelanocytic melanoma, lobular carcinoma and poorly differentiated ductal carcinoma take place. To distinguish primary breast lymphomas from those lesions, immunohistochemical staining and/or flow cytometry are helpful. In our case; LCA, CD20, CD43 showed diffusely and strong positivity while CD68 showed focal weak positivity with the absence of staining for pancytokeratin, EMA, HMB-45, CD117 and c-erbB-2 [10].

The therapeutic approach is contraversial due to the rarity of the reported cases. There is no certain establishment in the treatment $[1,10,13]$. The efficiency of surgery as a therapeutic approach is not significant. Like wise in our case, for a correct diagnosis, the necessity of the surgery is pointed out. Combination of chemotherapy and radiotherapy is recommended as the most effective treatment $[1,13]$. Histological grade and clinical stage are the main features for the prognosis of primary breast lymphoma [2,13,15].

\section{Conclusion}

As a conclusion, in the presence of a tumoral lesion on the breast, primary breast lymphomas must carefully be kept in mind regarding to the differences in the therapeutical approach and prognosis.

\section{REFERENCES}

[1] L. M. Sun, E. Y. Huang, F. Y. Meng, N. J. Chang, L. M. Chung, J. A. Liang, et al., "Primary Breast Lymphoma Clinically Mimicking Acute Mastitis: A Case Report," Tumori, Vol. 97, No. 2, 2011, pp. 233-235.

[2] A. Sanguinetti, M. Ragusa, R. Lucchini, M. Monacelli, F. Calzolari, C. Misso, et al., "Primary Breast Lymphoma: Case Reports and Review of the Literature,” Il Giornale di Chirurgia, Vol. 29, No. 5, 2008, pp. 230-232.

[3] K. Vaishnav, S. Shah, S. Pandhi and Y. Rathi, "Multifocal Bilateral Breast Masses in HIV-Positive Status," Indian Journal of Cancer, Vol. 48, No. 2, 2011, pp. 253255.doi:10.4103/0019-509X.82878

[4] D. Gupta, V. Shidham, V. Zemba-Palko and A. Keshgegian, "Primary Bilateral Mucosa Associated Lymphoid Tissue Lymphoma of the Breast with Atypical Ductal Hyperplasia and Localized Amyloidosis. A Case Report and Review of the Literature," Archives of Pathology \& Laboratory Medicine, Vol. 124, No. 8, 2000, pp. 12331236.

[5] S. M. Domchek, J. L. Hecht, M. D. Fleming, G. S. Pinkus and G. P. Canellos, "Lymphomas of the Breast: Primary and Secondary Involvement," Cancer, Vol. 94, No. 1, 2002, pp. 6-13. doi:10.1002/cncr.10163

[6] R. Giardini, C. Piccolo and F. Rilke, "Primary NonHodgkin's Lymphomas of the Female Breast,” Cancer, Vol. 69, No. 3, 1992, pp. 725-735.

[7] J. M. Xu, Q. Zha, X. M. Zuo and J. M. Tian, "Primary Non-Hodgkin's Lymphoma of the Breast: Mammography, Ultrasound, MRI and Pathologic Findings," Future Oncology, Vol. 8, No. 1, 2012, pp. 105-109. doi:10.2217/fon.11.132

[8] G. F. Ryan, D. R. Roos and J. F. Seymour, "Primary Non-Hodgkin's Lymphoma of the Breast: Retrospective Analysis of Prognosis and Patterns of Failure in Two Australian Centers," Clinical Lymphoma Myeloma and Leukemia, Vol. 6, No. 4, 2006, pp. 337-341. doi:10.3816/CLM.2006.n.010

[9] C. Wiseman and K. T. Liao, "Primary Lymphoma of the Breast,” Cancer, Vol. 29, No. 6, 1972, pp. 1705-1712.

[10] R. Baker, G. Slayden and W. Jennings, "Multifocal PriMary Breast Lymphoma,” Southern Medical Journal, Vol. 98, No. 10, 2005, pp. 1045-1048. doi:10.1097/01.smj.0000182173.05977.2e

[11] W. C. Jennings, R. S. Baker, S. S. Murray, C. A. Howard, D. E. Parker, L. F. Peabody, et al., "Primary Breast Lymphoma: The Role of Mastectomy and the Importance of Lymph Node Status,” Annals of Surgery, Vol. 245, No. 5, 2007, pp. 784-789. doi:10.1097/01.sla.0000254418.90192.59

[12] M. T. Liu, C. Y. Hsieh, A. Y. Wang, C. P. Pi, T. H. Chang, C. C. Huang, et al., "Primary Breast Lymphoma: A Pooled Analysis of Prognostic Factors and Survival in 93 Cases,” Annals of Saudi Medicine, Vol. 25, No. 4, 
2005, pp. 288-293.

[13] B. Mouna, B. Saber, El H. Tijani, M. Hind, T. Amina and E. Hassan, "Primary Malignant Non-Hodgkin's Lymphoma of the Breast: A Study of Seven Cases and Literature Review," World Journal of Surgical Oncology, Vol. 10, 2012, p. 151.

doi:10.1186/1477-7819-10-151

[14] G. Mpallas, G. Simatos, A. Tasidou, E. Patra, G. Gala- teros, G. Lakiotis, et al., "Primary Breast Lymphoma in a Male Patient,” Breast, Vol. 13, No. 5, 2004, pp. 436-438. doi:10.1016/j.breast.2003.11.002

[15] A. Neri, S. Caruso, G. Cerullo, M. P. Lenoci, D. Marrelli and F. Roviello, "Primary Non-Hodgkin's Breast Lymphoma: Surgical Approach,” Cases Journal, Vol. 1, No. 1, 2008, p. 311. doi:10.1186/1757-1626-1-311 